\title{
A Numerical Taxonomic Study of 100 Isolates of Corynebacterium pyogenes
}

\author{
By R. J. ROBERTS \\ Department of Veterinary Pathology, University of Glasgow
}

(Accepted for publication I3 April 1968)

\section{SUMMAR Y}

An Adansonian analysis was made on 100 isolates of Corynebacterium pyogenes with the aid of a digital computer. A wide variety of tests was used to define the isolates. The resulting dendrogram showed that $C$. pyogenes was a 'good species', with the IOO isolates related at high similarity values. No close affinity between biotype and host-species or between biotype and lesion was found, apart from the disposition within two adjacent groups of all of the isolates which originated from Swedish bulls.

\section{INTRODUCTION}

Corynebacterium pyogenes is a common pathogenic bacterium for all the larger domesticated animals. It is responsible for much economic loss and is present, as a primary or secondary invader, in almost all purulent conditions of cattle, sheep and pigs. The purpose of the present work was to study in detail a group of isolates of C. pyogenes isolated from a variety of animal hosts and morbid processes, and to utilize the information so obtained to estimate numerically with the aid of an electronic digital computer, the over-all similarity of the isolates. They were then to be disposed in a numerical classification, to ascertain whether any correlation obtained between such a classification and the species of host or the lesion of origin.

\section{METHODS}

A collection of 100 isolates of Corynebacterium pyogenes (53 from disease processes in cattle, including I9 strains from Sweden; 22 from pigs; 21 from sheep; three from wild rabbits, and one from a horse) was used. The isolates were maintained on $5 \%$ ( $/ \mathrm{v}$ ) blood agar, subcultured at weekly intervals and a new series of cultures was prepared monthly from a stock of freeze-dried cultures. Each isolate was subjected to the following tests:

A. Morphology. (I) Mean dimensions of bacteria grown under standard conditions. (2) Presence of basophilic cytoplasmic inclusions. (3) Evidence of extreme pleomorphism. (4) Presence of metachromatic granules.

B. Biochemistry. (I) Fermentation tests on arabinose, rhamnose, xylose, fructose, galactose, glucose, mannose, cellobiose, lactose, maltose, sucrose, trehalose, raffinose, dextrin, glycogen, inulin, starch, adonitol, dulcitol, erythritol, glycerol, mannitol, sorbitol, amygdalin, arbutin, coniferin, salicin. (2) Production of acetylmethylcarbinol, catalase, cytochrome (Deibel \& Evans, 1960), coagulase, lysine and arginine decarboxylase, dihydroxyacetone, $\beta$-galactosidase, hydrogen peroxide, indole, lecithi- 
nase, lipase, oxidase, phenylalanine deaminase, phosphatase, Tween hydrolase, reduction of methylene blue, methyl-red test (Barritt modification) and citrate utilization test (Koser, I923).

C. Growth tests. (I) Type of deposit in fluid media; turbidity of standard suspensions after incubation for $18 \mathrm{hr}$. (2) Production of soluble haemolysin.

D. Physical tests. (I) Slide auto-agglutination, in saline (pH 6.8); tube agglutination at various $\mathrm{pH}$ values; resistance to high salt concentration $(6 \%)$; growth at $46^{\circ}$; growth in lauryl sulphate broth $(0.01 \%)$; survival of culture at $4^{\circ}$; growth in potassium cyanide medium $(0.007 \%)$; growth in serum agar plates containing pyronin $(0.001 \%)$, methyl-violet $(0.002 \%)$ basic fuchsin $(0.004 \%)$ or thionine $(0.0033 \%)$; growth on MacConkey medium (with and without enrichment with $3 \%$ serum); growth on bismuth sulphite agar. (2) Sensitivity to bacitracin (I5 units), chloramphenicol (Io $\mu \mathrm{g}$.), sulphafurazole (I00 $\mu \mathrm{g}$.), neomycin (Io $\mu \mathrm{g}$.), nitrofurantoin (200 $\mu \mathrm{g}$.), penicillin $\mathrm{G}$ ( 15 units), polymyxin B (IOO units), streptomycin (IO $\mu \mathrm{g}$.), methicillin (1o $\mu \mathrm{g}$.), colistin (50 $\mu \mathrm{g}$.), fucidic acid (Io $\mu \mathrm{g}$.). kanamycin (5 $\mu \mathrm{g}$.), novobiocin (5 $\mu \mathrm{g}$.), cloxacillin ( $5 \mu \mathrm{g}$.), ampicillin ( $2 \mu \mathrm{g}$.).

Analysis of the results obtained for the hundred strains was done according to Adansonian principles of bacterial taxonomy modified according to Sneath (I962) for the purpose of computer analysis. The main endeavour was to distribute strains into groups or clusters, whereby each was composed of mutually similar strains. Tests where every strain gave a positive, or a negative result, were not incorporated in the data table. The results of the remaining tests (62), which gave variable results, were coded according to the requirements of Gower's CLASP programme, and estimation of coefficients of mutual similarity of the strains was made by J. C. Gower of Rothamsted Experimental Station. The programme used is capable of accepting information of three kinds-dichotomies ( + or -), quantitative (e.g. morphology measurements) and qualitative (e.g. litmus milk test, where mutually exclusive reactions, unrelated by rank, occur). Calculation of coefficients of similarity (S) were calculated and expressed in the form of a similarity matrix indicating the $S$ values for each strain relative to every other. The method of calculation of $S$ values in this programme does not take into account negative matches, for the reasons advanced by Sneath (1962). Cluster grouping was done by the technique of 'single link listing', a method devised by Dr J. E. Smith (personal communication, 1965) and described and successfully used by Hussaini (I965).

Diagrammatic representation of the groupings was by means of a dendrogram (Fig. I) which rendered affinities of strains and clusters of strains apparent.

\section{RESULTS}

The computer calculated values of $\mathrm{S}$ ranged from $55 \%$ to $85 \%$. Those values are indicated in the dendrogram (Fig. I) as horizontal lines at the appropriate value, linking the isolate, or group stems. Isolates which were joined in the dendrogram at values of $85 \%$ S, e.g. no. $87: 85$ were obviously closely related, whereas isolates linked at $55 \%$ were only distantly related. The percentage similarity of $68 \%$ was selected as a suitable value for definition of major groups, since at that value 93 of the 100 isolates were encompassed within five major groups.

Table I indicates the distribution of isolates from different host species among the 


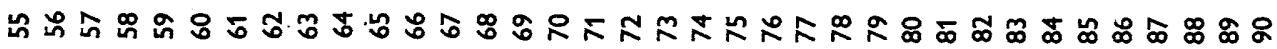

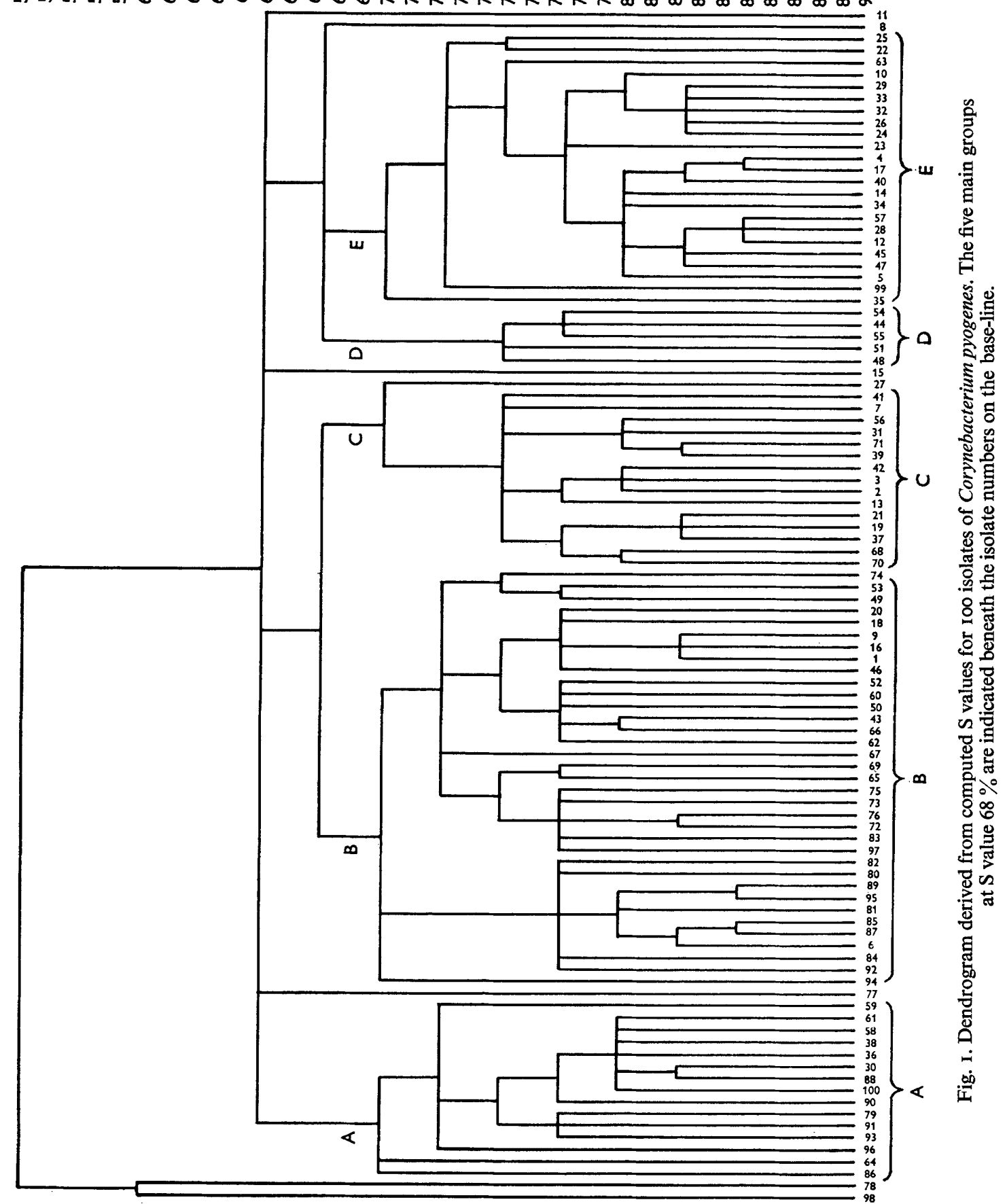

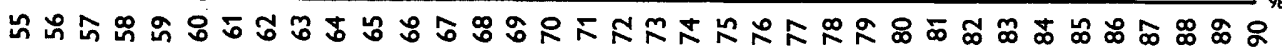


dendrogram defined groups. The most striking feature of Table $\mathrm{I}$ is that of the $\mathrm{I} 5$ isolates in group A only I was not of bovine origin. The distribution of isolates in groups $B$ and $\mathrm{E}$ was not considered significant, but in groups $\mathrm{C}$ and $\mathrm{D}$ the percentage of porcine isolates was much higher ( 47 and $60 \%$ ) than would accord with random distribution. Isolates from sheep were distributed evenly throughout the groups, except that there were no ovine isolates in group A.

Table 2 shows that while isolates from most parts of the body occurred uniformly throughout the groups, those recovered from the male genital tract were entirely confined to groups $\mathrm{A}$ and $\mathrm{B}$. The significance of that finding is difficult to assess because those isolates comprised 17 of the 18 isolates from Sweden, and the other isolate from that country, an ovine one (77) appeared in the dendrogram as an intermediate between groups A and B.

Table I. Distribution of roo Corynebacterium pyogenes isolates amongst the computer-defined groups

\begin{tabular}{|c|c|c|c|c|c|c|c|}
\hline \multirow[b]{2}{*}{ Host species } & \multirow{2}{*}{$\begin{array}{l}\text { No. of } \\
\text { isolates }\end{array}$} & \multicolumn{5}{|c|}{ Computer-defined groups } & \multirow{2}{*}{$\begin{array}{l}\text { Miscel- } \\
\text { laneous }\end{array}$} \\
\hline & & $\mathbf{A}$ & B & $\mathrm{C}$ & D & $\mathbf{E}$ & \\
\hline $\mathrm{Ox}$ & 53 & $14(94)$ & $20(57)$ & $3(20)$ & $\circ(-)$ & $12(52)$ & $4(57)$ \\
\hline Sheep & $2 I$ & $0(-)$ & $8(23)$ & $4(27)$ & I (20) & $7(30)$ & I (I4) \\
\hline Pig & 22 & I (6) & $5(14)$ & $7(47)$ & $3(60)$ & $4(17)$ & $2(29)$ \\
\hline Others & 4 & $o(-)$ & $2(6)$ & I (7) & I (20) & $0(-)$ & $0(-)$ \\
\hline All species & 100 & I5 & 35 & 15 & 5 & 23 & 7 \\
\hline
\end{tabular}

The number of isolates is given (followed in parentheses by the percentage) in relation to the number of isolates in each computer-defined group.

Table 2. Distribution of roo Corynebacterium pyogenes isolates from different organs or pathological conditions amongst the computer-defined groups

\begin{tabular}{|c|c|c|c|c|c|c|c|}
\hline \multirow{2}{*}{$\begin{array}{l}\text { Organ or } \\
\text { pathological } \\
\text { condition }\end{array}$} & \multirow{2}{*}{$\begin{array}{l}\text { No. of } \\
\text { isolates }\end{array}$} & \multicolumn{5}{|c|}{ Computer-defined groups } & \multirow[b]{2}{*}{ Miscellaneous } \\
\hline & & A & B & C & D & $\mathbf{E}$ & \\
\hline $\begin{array}{l}\text { Male genital } \\
\text { tract }\end{array}$ & 17 & $6(40)$ & II (3I) & $\circ(-)$ & $o(-)$ & $\circ(-)$ & $\circ(-)$ \\
\hline $\begin{array}{l}\text { Female geni- } \\
\text { tal tract }\end{array}$ & 5 & I (7) & I (3) & $2(13)$ & $\circ(-)$ & I (4) & $\circ(-)$ \\
\hline Mastitis & 21 & $5(33)$ & $6(17)$ & $\circ(-)$ & $\circ(-)$ & $7(30)$ & $3(44)$ \\
\hline Nephritis & 3 & I (7) & I (3) & I (7) & $0(-)$ & $0(-)$ & $0(-)$ \\
\hline Arthritis & 4 & $0(-)$ & I (3) & $2(13)$ & o (-), & I (4) & $0(-)$ \\
\hline $\begin{array}{l}\text { Respiratory } \\
\text { tract including } \\
\text { pneumonia }\end{array}$ & 16 & $0(-)$ & $6(17)$ & $4(27)$ & $2(40)$ & $4(17)$ & $\circ(-)$ \\
\hline Abscesses & 15 & 2 (I3) & 5 (I4) & I (7) & $2(40)$ & $3(13)$ & $2(28)$ \\
\hline $\begin{array}{l}\text { Lymph-node } \\
\text { lesions }\end{array}$ & I I & $0(-)$ & I (3) & 2 (I3) & I $(20)$ & $5(22)$ & $2(28)$ \\
\hline Unknown & 8 & $0(-)$ & $3(9)$ & $3(20)$ & $\circ(-)$ & $2(9)$ & $\circ(-)$ \\
\hline All sources & 100 & 15 & 35 & I5 & 5 & 23 & 7 \\
\hline
\end{tabular}

The number of isolates is given (followed in parentheses by the percentage) in relation to the number of isolates in each computer-defined group. 


\section{DISCUSSION}

The results of this work indicate that the group of Ioo isolates of Corynebacterium pyogenes studied was a closely knit group possessed of many features common to all isolates. The results of the computer analysis show that $C$. pyogenes merits the description 'good species' since all the isolates used were linked at high similarity values similar to those obtained, for example, by Smith \& Thal (1965) with the genus Pasteurella.

Cluster analysis of the computed ' $\mathrm{S}$ ' values indicated close affinity between the 100 Corynebacterium pyogenes isolates used here, but did not define any marked relationship between biotype, and lesion of origin (with the exception of the confinement of isolates from Swedish bulls to groups A and B). This suggests that, in Britain at least, biotypes are not limited to a single host or lesion, and that cross-infection among sheep cattle and pigs, as well as infection from feral hosts such as wild rabbits, is perfectly feasible.

I wish to acknowledge the advice and assistance rendered by Dr J. C. Gower, of Rothamsted, and Dr J. E. Smith, University of Surrey, and the technical assistance of Mr D. H. Ramsay.

\section{REFERENCES}

Deibel, R. H. \& Evans, J. B. (I960). A modified Benzidine test for detection of cytochrome containing respiratory systems in micro-organisms. J. Bact. 79, 356.

Hussaini, S. N. (1965). A taxonomic study of Pasteurella multocida. Ph.D. thesis, University of London.

Koser, S. A. (1923). Utilization of the salt of organic acids by the coli-aerogenes group. J. Bact. 8, 493 .

Smith, J. E. \& Thal, E. (1965). A taxonomic study of the genus Pasteurella using a numerical technique. Acta path. microbiol. scand. 66, 213.

SNeAth, P. H. A. (1962). The construction of taxonomic groups. Symp. Soc. gen. Microbiol. 12, 289. 